\title{
3-D printed sensing patches with embedded polymer optical fibre Bragg gratings
}

\author{
Zubel, Michal G.; Sugden, Kate; Saez-Rodriguez, D.; Nielsen, Kristian; Bang, Ole
}

\section{Published in:}

Proceedings of SPIE

Link to article, DOI:

$10.1117 / 12.2237495$

Publication date:

2016

Document Version

Publisher's PDF, also known as Version of record

Link back to DTU Orbit

Citation (APA):

Zubel, M. G., Sugden, K., Saez-Rodriguez, D., Nielsen, K., \& Bang, O. (2016). 3-D printed sensing patches with embedded polymer optical fibre Bragg gratings. In Proceedings of SPIE (Vol. 9916). [99162E] SPIE -

International Society for Optical Engineering. Proceedings of SPIE - The International Society for Optical Engineering https://doi.org/10.1117/12.2237495

\section{General rights}

Copyright and moral rights for the publications made accessible in the public portal are retained by the authors and/or other copyright owners and it is a condition of accessing publications that users recognise and abide by the legal requirements associated with these rights.

- Users may download and print one copy of any publication from the public portal for the purpose of private study or research.

- You may not further distribute the material or use it for any profit-making activity or commercial gain

- You may freely distribute the URL identifying the publication in the public portal 


\title{
3-D printed sensing patches with embedded polymer optical fibre Bragg gratings
}

\author{
Michal G. Zubel ${ }^{\mathrm{a}^{*}}$, Kate Sugden ${ }^{\mathrm{a}}$, D. Saez-Rodriguez ${ }^{\mathrm{b}}$, K. Nielsen ${ }^{\mathrm{c}}$, O. Bang ${ }^{\mathrm{c}}$ \\ ${ }^{a}$ Aston Institute of Photonic Technologies, Aston University, B4 7ET Birmingham, United Kingdom \\ ${ }^{\mathrm{b}}$ Comunicaciones Opticas, Universidad Politecnica de Valencia, Valencia 46022, Spain \\ ${ }^{c}$ DTU Fotonik, Department of Photonics Engineering, DK-2800 Kgs. Lyngby, Denmark
}

\begin{abstract}
The first demonstration of a polymer optical fibre Bragg grating (POFBG) embedded in a 3-D printed structure is reported. Its cyclic strain performance and temperature characteristics are examined and discussed. The sensing patch has a repeatable strain sensitivity of $0.38 \mathrm{pm} / \mu \varepsilon$. Its temperature behaviour is unstable, with temperature sensitivity values varying between $30-40 \mathrm{pm} /{ }^{\circ} \mathrm{C}$.
\end{abstract}

Keywords: polymer optical fibre, fibre Bragg grating, FBG, POFBG, additive layer manufacturing, 3-D printing, strain sensor, temperature sensor

\section{INTRODUCTION}

Polymer optical fibre Bragg gratings (POFBGs) are an emerging yet promising family of optical fibre sensors. They possess unique properties, giving them certain advantages over silica fibre Bragg gratings (FBGs). Qualities of POFBGs include much lower elastic modulus (3.3 GPa) compared to their silica counterparts ( $73 \mathrm{GPa}$ ), much higher flexibility, biocompatibility, and ease of chemical modification, allowing for tuning their properties (e.g. rendering them sensitive or insensitive to humidity $)^{1}$. These properties led to new applications in for instance as distant fields as medicine ${ }^{2,3}$ and aviation industry ${ }^{4}$.

3-D printing, also known as additive layer manufacturing (ALM), is a common name for a group of techniques that have been revolutionising the field of manufacturing over the last few years ${ }^{5,6}$. Multitude of materials, versatility of reproducible structural shapes, much shortened delay between design and final production phase, as well as ease of customisability count among many qualities that made ALM see such a tremendous development, and which make ALM be considered the manufacturing technology of the future.

This study attempts to combine the qualities of POFBGs and fused deposition modelling (FDM), which is one of the most popular 3-D printing technique. This combination is viewed as an important step forward in fast and easy fabrication of optical fibre sensors of potentially unprecedented properties.

The paper demonstrates for the first time embedding of two in-house fabricated POFBGs into an FDM-manufactured sensing patches of different material. Response to cyclic strain application and temperature is described and discussed, outlining potential benefits and challenges.

\section{POFBG INSCRIPTION}

Two POFBGs were inscribed by scanning a UV beam across a phase mask ${ }^{7}$ using a highly-photosensitive $125 \mu \mathrm{m}$ microstructured POF made of poly(methyl methacrylate) (PMMA) doped with benzyl dimethyl ketal (BDK) ${ }^{8}$. A Kimmon $325 \mathrm{~nm} \mathrm{HeCd}$ laser ( $35 \mathrm{~mW}$, model IK3301 R-G) and an Ibsen Photonics custom-made phase mask (557.50 nm pitch) were used during the inscription process. The scanning length, speed and time of the first grating (POFBG1) was $10 \mathrm{~mm}, 2.6 \mu \mathrm{m} / \mathrm{s}$ and $53 \mathrm{~min}$ respectively. The inscription parameters for the second grating (POFBG2) were $5.2 \mathrm{~mm}$, $2.2 \mu \mathrm{m} / \mathrm{s}$ and $30 \mathrm{~min}$ respectively. The resulting POFBGs had Bragg wavelength of $828.9 \mathrm{~nm}$ and peak reflected power of $-63.1 \mathrm{dBm}$ (POFBG1), and $828.3 \mathrm{~nm}$ and $-68.4 \mathrm{dBm}$ (POFBG2) respectively.

*m.zubel@aston.ac.uk

Sixth European Workshop on Optical Fibre Sensors, edited by Elfed Lewis, Proc. of SPIE Vol. 9916, 99162E · (C) 2016 SPIE · CCC code: 0277-786X/16/\$18 · doi: 10.1117/12.2237495 


\section{POFBG EMBEDDING}

The sensing patches housing POFBG were 3-D printed using an UP! printer (model 3DP-14-4A). They were glued in the sensing patches using (3-(trimethoxysilyl)propyl)ethylene-diamine. It is a common elastic glue, which initially bonds in 5 min, and fully cures in 1 hour.

The design of the sensing patches contained a POF embedding channel, whose bottom was at the neutral axis of the beam region (see Figure 1b). The process was paused midway, at the point where the full depth of the embedding channel was printed and just before deposition of the layer that was about to cover it. Then the glue was deposited at the bottom of the channel and along the POF in order to provide optimal glue distribution. The fibre was inserted in the structure and moved forth and back along the channel multiple times to assure that it was at the bottom of the channel. The fibre was mounted with tape on temporary supports at both fibre inlets, and the glue was allowed to cure for $15 \mathrm{~min}$ to provide initial bonding. Subsequently, the temporary supports were removed and the printing process was resumed, leading to full development of the sensing patch.

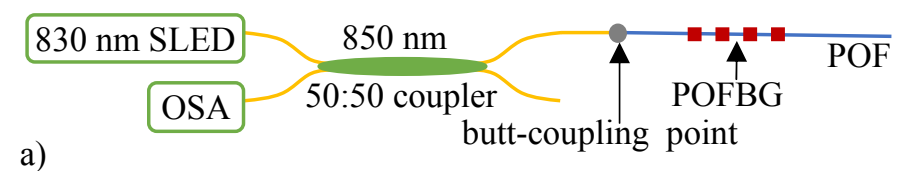

b)

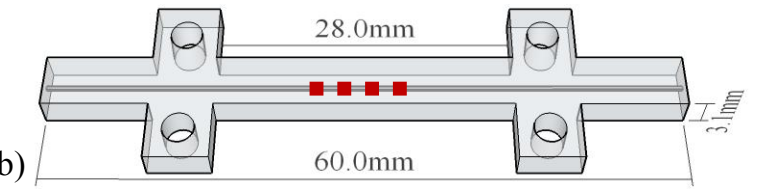

Figure 1. a) Experimental setup, b) 3-D view of the POFBG housing structure (POFBG location marked with dotted line).

POFBG1 was embedded in the first 3-D printed patch, which had the channel depth of $300 \mu \mathrm{m}$. It was printed with acrylonitrile butadiene styrene (ABS), a popular structural material for ALM. The temperature of the printing nozzle was $260^{\circ} \mathrm{C}$, and this of the printing bed was $105^{\circ} \mathrm{C}$. Although the grating reflection was still observable, the strength of the Bragg reflection peak dropped by $8.5 \mathrm{~dB}$, and a regular single-peak-shaped reflection transformed into a broad spectrum of a few distinct maxima.

There are multiple factors that could result in such deterioration of grating characteristics. The most significant issue is the temperature of the printing nozzle and bed. The latter is comparable with the glass transition temperature of PMMA, whereas the former is much higher. To overcome this two changes were made: the structural material was changed to polylactic acid (PLA), which prints at nozzle and bed temperatures of $230{ }^{\circ} \mathrm{C}$ and $50{ }^{\circ} \mathrm{C}$, respectively; the channel depth was increased to $750 \mu \mathrm{m}$, allowing for a thicker glue layer isolating the fibre from the nozzle temperature and a shorter POFBG was used to avoid differential chirping due to uneven strain. Using this modified approach the grating withstood printing, and there was no observable change to the shape of the response peak. POFBG2 showed initial reflection peak power dip of $1 \mathrm{~dB}$.

\section{CHARACTERISATION OF THE 3-D PRINTED STRUCTURE}

\subsection{Strain response}

The strain response of the sensing patch was measured by clamping down one side of the structure to an immobilised support, and the other one to a translation stage of $20 \mu \mathrm{m}$ accuracy, so that only the middle beam part of the structure was being strained. 3 straining cycles in room temperature were performed, each comprising of gradual strain increase and decrease. The sample was left to relax between the cycles for a few hours. After each strain change the Bragg peak position was measured at different time intervals: at $\mathrm{t}=0 \mathrm{~min}, 1 \mathrm{~min}$, and $5 \mathrm{~min}$. The first data series $(\mathrm{t}=0 \mathrm{~min})$ was plotted in Figure 2a. There was no measurable difference between the data collected at different time intervals, apart from the final part of strain decrease region in each cycle, where some hysteresis became apparent, Figure $2 \mathrm{~b}$.

The translation stage used was only able to exert tensile force on the sample, and not compressive one. The first point in Figure 2a in each strain increase cycle is the last stage displacement division at which no change to Bragg peak was visible. The second point in each cycle was the first stage displacement division that caused Bragg peak change. Thus, although plots in Figure 2a suggest the first point in each series to be the beginning of strain build-up, in the reality it was somewhere between the first and the second data point. This inaccuracy resulted in a systematic error of up to $0.02 \mathrm{~mm}$, which did not change meaning of the results.

The strain increase in cycle 1 was the least linear of all. This can perhaps be linked with the POF taking optimal position within the sample, compensating for any possible slack remaining from the embedding stage. The strain decrease in 
cycle 1 showed good linearity down to $0.10 \mathrm{~mm}$ displacement value. The strain increase in cycles 2 and 3 started at a higher value of stage displacement, which suggests that there was a permanent increase in the sample length between straining cycles. Moreover, there was a non-linear strain increase at lower stage displacement values, as opposed to what was observed in cycle 1, and what is considered a regular POFBG response to strain 9 . Possibly such a behaviour is linked to material fatigue coming from overstressing or cyclic stressing of the sample, but the mechanics of material relaxation also influence the sample behaviour.
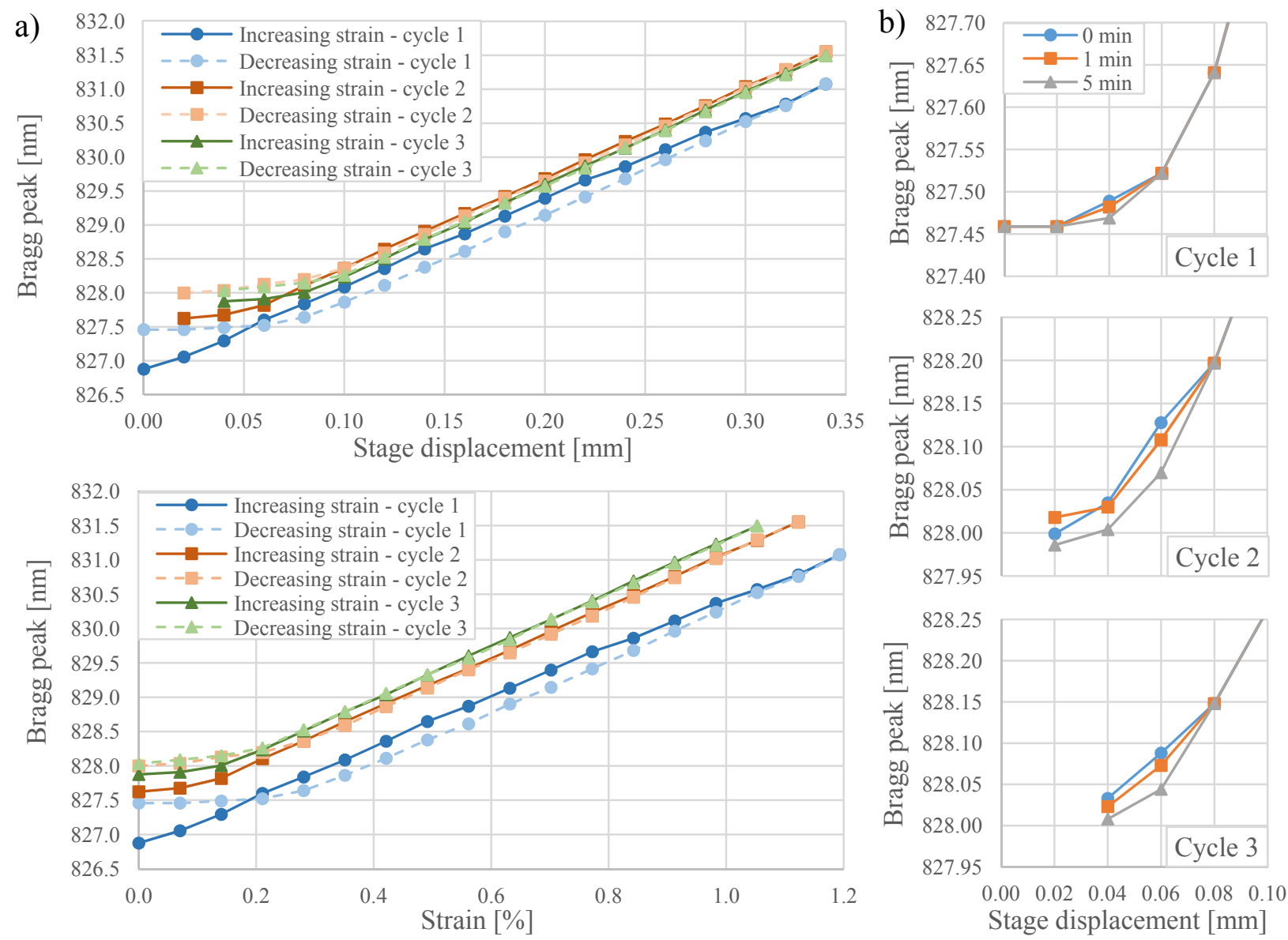

Figure 2. (a) Bragg reflection peak immediately after strain change in the function of testing stage displacement and strain,

(b) strain decrease hysteresis of Bragg reflection peak at different time intervals

The strain increase and decrease in the linear range of cycles 2 and 3 had almost the same slope as in strain decrease of cycle 1 and suggests that strain sensitivity of the patch would remain constant on longer term operation.

Unexpectedly, strain sensitivity of the patch (excluding strain increase in cycle 1) was $0.38 \mathrm{pm} / \mu \varepsilon$, which was some 3.5 times lower than usual values found in the literature ${ }^{1,9}$. A speculative explanation of this may be that the glue shielded a bigger part of the stress exerted on the POF, but a definite answer would need more investigation.

The hysteresis of strain response is biggest in the first cycle $(580 \mathrm{pm})$, and gradually decreases in the consecutive ones, yielding $380 \mathrm{pm}$ in the second and $160 \mathrm{pm}$ in the third cycle. It does not change much over the timescale on which it was measured - the biggest change of $30 \mathrm{pm}$ was observed after $5 \mathrm{~min}$ in cycle 3 . It is noted that the hysteresis manifested itself at the same stage displacement position (around $0.08-0.10 \mathrm{~mm}$ ) and so could be related to the equipment.

\subsection{Temperature response}

In order to stabilise temperature performance of the POFBG, the sensing patch was annealed for 3 hours at $55{ }^{\circ} \mathrm{C}$ (more than $10{ }^{\circ} \mathrm{C}$ above maximal intended temperature of operation). At the end of the annealing the Bragg wavelength had decreased by $13.92 \mathrm{~nm}$ to $814.08 \mathrm{~nm}$. The temperature response of the sensing patch was examined placing the sample 
on a hotplate under a thermo-insulating cover and measuring the temperature with a mercury thermometer, Figure 3 . The maximum temperature during the test was $\sim 43{ }^{\circ} \mathrm{C}$, as this is enough for most medical applications and bio-applications. The thermal stabilisation achieved was found not to be complete, because the thermal testing cycle resulted in grating or structure annealing by further $220 \mathrm{pm}$. The resulting temperature sensitivity was $30-40 \mathrm{pm} /{ }^{\circ} \mathrm{C}$, whereas usually reported values are of similar magnitude but negative ${ }^{1}$. Nevertheless, is has to be noted that the temperature response of POF is often fibre-dependent, and strongly depends on humidity ${ }^{1}$.

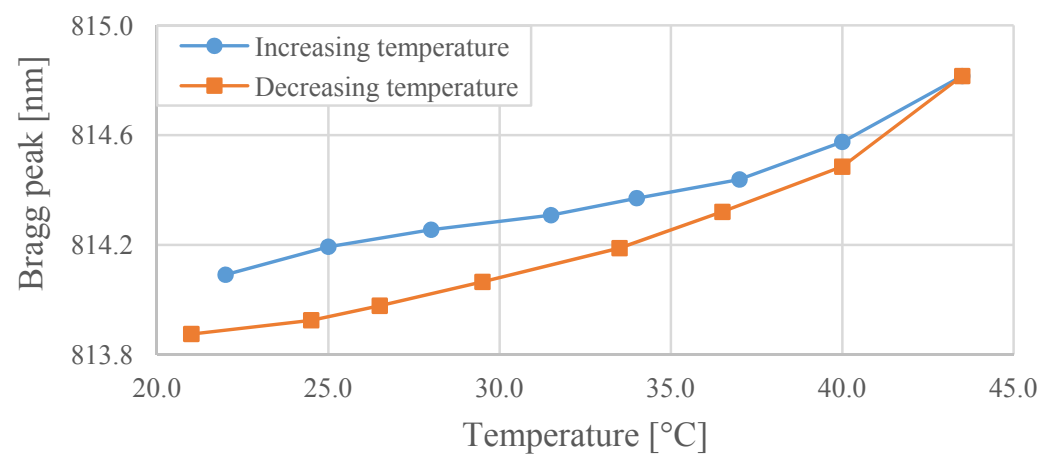

Figure 3. Temperature response of the embedded POFBG.

\section{CONCLUSIONS}

In this paper the first demonstration of embedding a POFBG into a 3-D printed structure was reported. This is expected to facilitate rapid, flexible and easily-customisable optical fibre sensor production in the future. Strain sensitivity of 0.38 $\mathrm{pm} / \mu \varepsilon$ is $\sim 3.5$ times smaller than values usually found in the literature. The authors are undertaking further investigation to find the reason of such behaviour. The thermal stability of the embedded POFBG was shown to be an issue, which would prevent many practical applications. The authors will be investigating further ways of stabilising thermal performance of POFBGs, including pre-inscription and pre-embedding grating annealing.

\section{ACKNOWLEDGEMENT}

The research leading to these results has received funding from the People Programme (Marie Curie Actions) of the European Union's Seventh Framework Programme FP7/2007-2013/ under REA grant agreement n 608382.

\section{REFERENCES}

[1] D. J. Webb, [Polymer Fibre Bragg Grating Sensors and their Applications] CRC Press, United Kingdom(2015).

[2] C. Broadway, D. Gallego, G. Woyessa et al., "Polymer optical fibre sensors for endoscopic optoacoustic imaging." 9539.

[3] C. Broadway, D. Gallego, G. Woyessa et al., "Fabry-Perot micro-structured polymer optical fibre sensors for opto-acoustic endoscopy." 9531.

[4] C. A. F. Marquess, A. Pospori, D. Sáez-Rodríguez et al., "Fiber-optic liquid level monitoring system using microstructured polymer fiber Bragg grating array sensors: Performance analysis." 9634.

[5] S. H. Huang, P. Liu, A. Mokasdar et al., "Additive manufacturing and its societal impact: A literature review," International Journal of Advanced Manufacturing Technology, 67(5-8), 1191-1203 (2013).

[6] T. J. Horn, and O. L. A. Harrysson, "Overview of current additive manufacturing technologies and selected applications," Science Progress, 95(3), 255-282 (2012).

[7] H. Dobb, D. J. Webb, K. Kalli et al., "Continuous wave ultraviolet light-induced fiber Bragg gratings in fewand single-mode microstructured polymer optical fibers," Optics letters, 30(24), 3296-8 (2005).

[8] D. Saez-Rodriguez, K. Nielsen, H. K. Rasmussen et al., "Highly photosensitive polymethyl methacrylate microstructured polymer optical fiber with doped core," Optics Letters, 38(19), 3769--3772 (2013).

[9] A. Abang, and D. J. Webb, "Influence of mounting on the hysteresis of polymer fiber Bragg grating strain sensors," Optics Letters, 38(9), 1376-1378 (2013). 